\title{
Oral Nevi presenting as a kissing lesion on Lip: A case report
}

\author{
Dr.Surej Kumar L.K ${ }^{1,}$ Dr. Varun Menon. $\mathrm{P}^{2}$ \\ ${ }^{1}$ (Professor \& HOD Department of Oral \& Maxillofacial Surgery, PMS College of Dental Science \& \\ Research,Trivandrum,India) \\ ${ }^{2}$ (Junior Resident Department Of Oral \& Maxillofacial Surgery, PMS College of Dental Science \& \\ Research,Trivandrum,India)
}

\begin{abstract}
Nevi are benign proliferations of nevus cells located either entirely within the epithelium, in both the epithelium and underlying stroma, or in the subepithelial stroma alone. They are best categorized as hamartomas rather than true neoplasms. Nevi of the oral cavity are usually called mucosal melanocytic nevi or intramucosal nevi.These are uncommon oral lesions causing focal pigmentation. Melanotic nevi are benign melanocytic tumours originating from defective melanoblasts of the neural crest. Clinically, it is an asymptomatic, flat or slightly elevated lesion of brown or brown-black colour. It is usually located on the palate and buccal mucosa and rarely on the gingival and vermillion border of lips. Based on histological criteria, intraorally four types of nevi have been described: the intramucosal, junctional, compound and blue.

In this article, we are reporting a case of oral pigmented lesion in a female patient on upper and lower vermillion border of lip giving an appearance of a kissing lesion which was histopathogically diagnosed as intramucosal nevus.
\end{abstract}

Key words: Kissing lesion, oral melanotic nevi, pigmentation, vermillion border of lip

\section{Introduction}

Oral pigmentation may be exogenous or endogenous in origin. Exogenous pigmentation is commonly due to foreign-body implantation in the oral mucosa. Endogenous pigments include melanin, haemoglobin, hemosiderin and carotene. Melanin is produced by melanocytes in the basal layer of the epithelium and is transferred to adjacent keratinocytes via membrane-bound organelles called melanosomes. Melanin is also synthesized by nevus cells, which are derived from the neural crest and are found in the skin and mucosa. Pigmented lesions caused by increased melanin deposition may be brown, blue, grey or black, depending on the amount and location of melanin in the tissues ${ }^{1}$. Pigmented nevi are rare causes of focal oral pigmentation. They present as either brown or blue lesions. Histologically, nevi are composed of an accumulation of nevus cells in the basal epithelial layers, the connective tissue or both. Oral nevi are uncommon oral mucosal lesions usually caused by benign proliferations of nevus cells located either entirely within the epithelium, in both the epithelium and underlying stroma, or in the subepithelial stroma alone. They are best categorized as hamartomas rather than true neoplasms.

\section{Case Report:}

A 39 year old female patient reported to our department with brownish black discolouration both on upper and lower lip "Fig1" \& "Fig 2", she had noticed the lesion for fairly long time and was cancerophobic about the lesion, and also because of the aesthetic reasons she wanted the lesion to be removed. Histopathology showed stratified squamous parakeratinized epithelium in cellular connective tissue, the subepithelial region shows aggregates of nevus cells and abundant melanin, the diagnosis came as intramucosal Nevus "Fig3" \&"Fig 4". The lesion was Excised and Sutured "Fig5" \& "Fig6"

\section{Discussion:}

Oral melanocytic nevi are benign tumours of melanocytes, the pigment producing cells found in the skin and in juxtacutaneous mucous membranes, including the oral mucosa. ${ }^{2}$ While cutaneous melanocytic nevi of young adult Caucasians number in the dozens, Oral melanocytic nevi are rare, and their etiology and pathogenesis are poorly understood. ${ }^{3,4}$

In 1943 first documented case of intraoral nevus was reported by Field and Ackermann ${ }^{5}$, the term intralamina propria nevus was first proposed by Comerford ${ }^{6}$.Later King et al adopted the term, intramucosal nevus. It most frequently occurs in female patients and in the third and fourth decades of life. The mean ages of patients with oral nevi are between 30 and 38 years. The common site for occurrence being hard palate, followed by the buccal mucosa and least seen on vermilion $\operatorname{border}^{8}$.In our case the lesion was seen not only on the vermillion border of lower lip but also on the upper lip giving an impression of kissing lesion 
Regarding morphogenesis, the melanocytic proliferation can be divided into 3 phases: 1) proliferation of benign neoplastic melanocytes along the epithelial mesenchymal junction (junctional nevus); 2) migration of these cells into the mesenchymal compartment (compound nevi); and 3) loss of the junctional component of the nevus, so that all remaining nevomelanocytes are located within the subepithelial compartment (subepithelial nevi) ${ }^{2,9,10}$, As in this case it was subepithelial nevi "Fig3".

Histologically based on location of the nevus cells, cutaneous nevi can be classified into 3 groups. The first group, junctional nevus, is when nevus cells are limited to the basal cell layer of the epithelium. The second group, compound nevus, is used if the cells are in the epidermis and dermis. The third group, intradermal nevus, is when nests of nevus cells are entirely in the dermis. In Oral nevi intradermal nevus is replaced by the term intramucosal nevus. Histopathological report showed the case was an intramucosal nevus "Fig4".

Nevi may also be classified as congenital or acquired. The etiology and pathogenesis of Oral melanocytic nevi are poorly understood even though, as for their cutaneous counterpart, oncogenic mutations of genes coding for components of the RAS signaling pathways may play a role. ${ }^{11}$

Congenital and dysplastic nevi have an increased risk for transformation to cutaneous malignant melanoma, but these nevi are rare or absent in the mouth. Complications may be related to treatment by means of simple excision. These complications may be minor. Only one case of recurrent nevus in the oral cavity is reported ${ }^{3}$. Although the use of lasers has been reported for the treatment of pigmented lesions (melasma, senile keratosis, congenital nevus), the results for congenital nevus have been unsuccessful because the deeper portions of the nevi are unaffected by the laser, laser-induced malignant transformation of naevus cells remains a theoretical concern but such concerns have not been found to be true in clinical practice. Its application in removal of oral nevi still needs a lot of research. The overall prognosis of oral nevi is excellent.

\section{Figures}

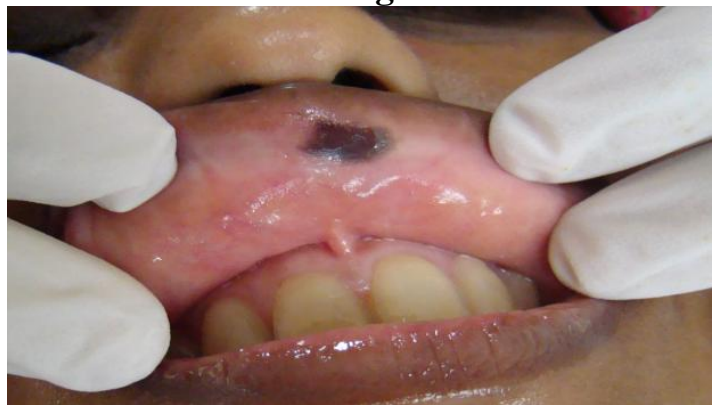

Fig1: Lesion on vermillion border of upper lip

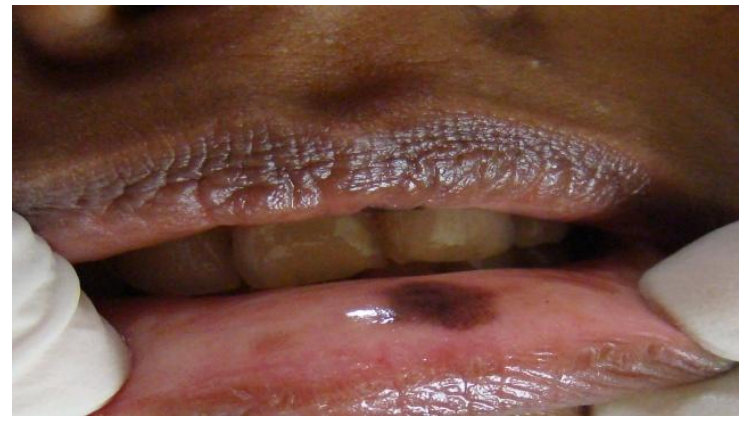

Fig2: Lesion on vermillion border of lower lip

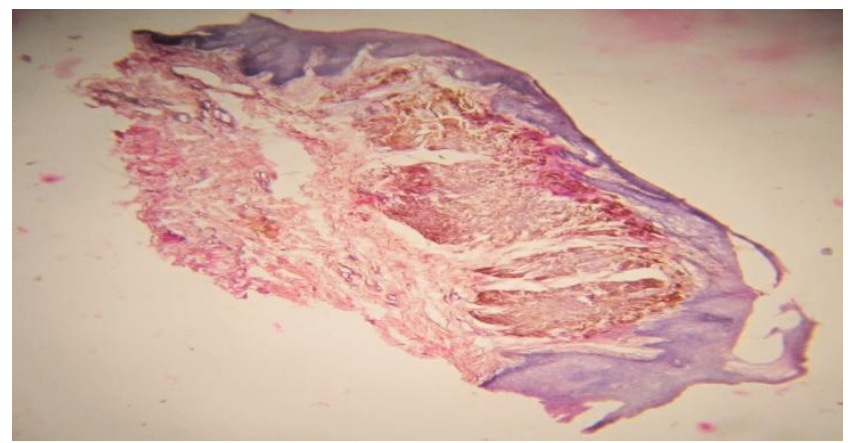

Fig3: Lesion under low power 


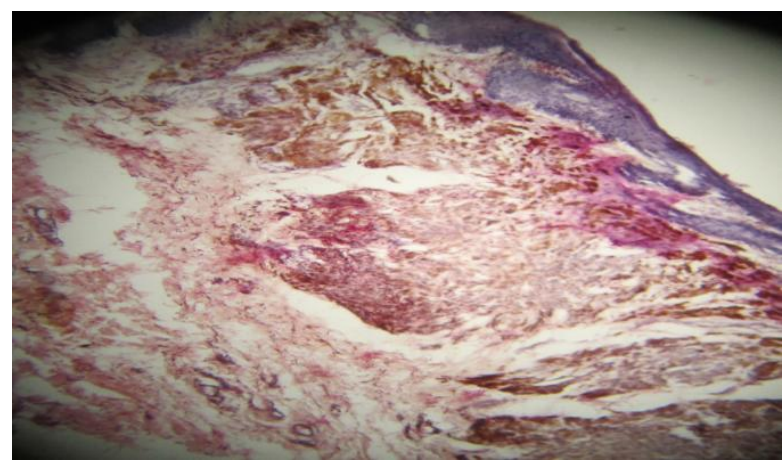

Fig4: Lesion under high power

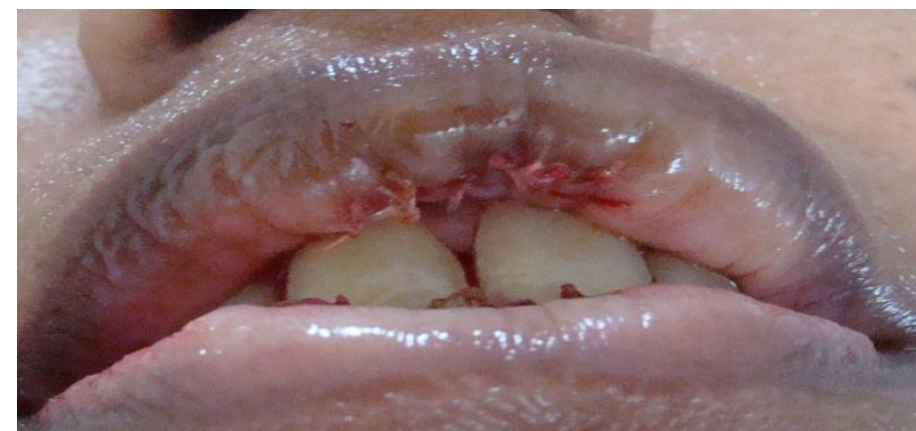

Fig5: Lesion excised and sutured

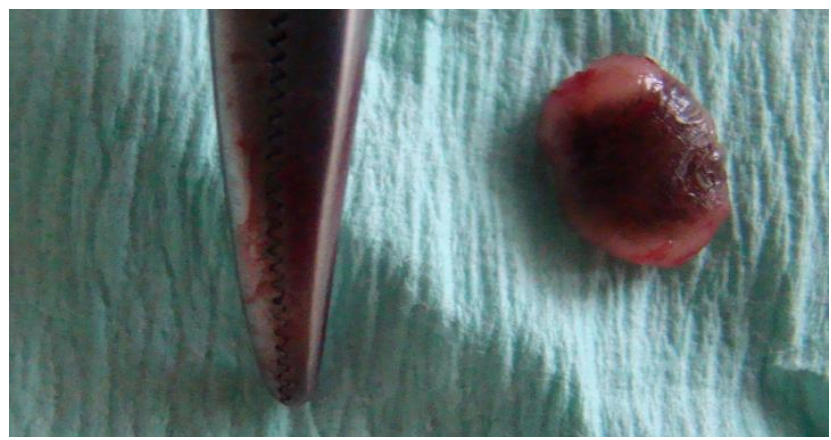

Fig6: Excised Specimen

\section{Conclusion:}

The potential for oral nevi to undergo malignant transformation is still an enigma because of the paucity of reported cases and the limited follow-up, because the malignant potential of oral nevi is still uncertain and because preexisting macular pigmentation is present in about one third of all patients with oral melanoma, it is advisable to remove all pigmented lesions suspected to be melanocytic nevi.

\section{REFERENCES}

[1]. Eisen D. Disorders of pigmentation in the oral cavity. Clin Dermatol 2000; 18(5):579-87.

[2]. Grichnik JM, Rodhes AR, Sober AJ. Benign hyperplasias and neoplasias of melanocytes. In: Lever's hystopathology of the skin. 7th ed., 2005. p. 889 [chapter 91].

[3]. MacKie RM, English J, Aitchinson TC, Fitzsimonos CP, Wilson P. The number and distribution of benign pigmented moles (melanocytic nevi) in healthy British population. Br J Dermatol 1985;113(2):167-74

[4]. Buchner A, Merrel PW, Carpenter WM. Relative frequency of solitary melanocytic lesions of the oral mucosa. J Oral Pathol Med 2004;33(4):550-7.

[5]. Field HJ, Ackerman AA. Non-pigmented nevus on labial mucosa. Am J Orthodontics Oral Surg. 1943;29:180-1

[6]. Comerford TE Jr, Delapava S, Pickren JW. Nevus of the oral cavity. Oral Surg Oral Med Oral Pathol. Feb 1964;17:148-51.

[7]. King OH Jr, Blankenship JP, King WA, Coleman SA. The frequency of pigmented nevi in the oral cavity. Report of five cases. Oral Surg Oral Med Oral Pathol. Jan 1967;23(1):82-90

[8]. Craig L. Hatch. Pigmented lesions of the oral cavity. Dental Clinics of North America 2005; 49(1):185-20

[9]. Fitzpatrick TB, Breatnach AS. Das epidermale melanin-einheitsystem.Dermatol Wschr 1963;147:481-9.

[10]. Mooi WJ, Kraus T. Biopsy pathology of melanocytic disorders.Biopsy pathology series 17. London; Chapman and Hall Medical;1991. p. 346.

[11]. Takata M, Saida T. Genetic alterations in melanocytic tumors. J Dermatol Sci 2006;43:1-10. 